\title{
Quantitative Analysis of CD4+ T Cell Function in the Course of Human Immunodeficiency Virus Infection

\author{
Gradual Decline of Both Naive and Memory Alloreactive T Cells
}

\author{
Linde Meyaard, Sigrid A. Otto, Berend Hooibrink, and Frank Miedema \\ Department of Clinical Viro-Immunology, Central Laboratory of the Netherlands Red Cross Blood Transfusion Service and the \\ Laboratory of Experimental and Clinical Immunology of the University of Amsterdam, 1066 CX Amsterdam, The Netherlands
}

\begin{abstract}
Early in human immunodeficiency virus (HIV) infection CD4+ and CD8 + $T$ cells are qualitatively affected. Loss of responses to recall antigen precedes impaired responses to allogeneic MHC and mitogens. The selective quantitative loss of memory $\mathbf{T}$ cells in early infection, only partially explains the observed defects. We investigated whether functional loss of $\mathbf{T}$ cells is preferentially observed for memory $T$ cells or whether both naive and memory $T$ cell subsets are affected in the course of HIV infection. We studied the proliferative response of CD4 $+\mathrm{T}$ cells from $\mathrm{HIV}$-infected individuals to alloantigens, to which normally both naive and memory $T$ cells respond, by limiting dilution analysis. The decreased proliferative response to alloantigens in HIVinfected individuals was associated with a decreased precursor frequency of alloreactive cells. The frequency was decreased in both the CD45RA + (naive) and the CD45RO+ (memory) subset of CD4+ T cells. Analysis of four individuals in the course of HIV infection revealed similar kinetics of the decline in function in both subsets.

Although initially $T$ cell defects may be accounted for by the selective quantitative loss of memory cells, in later stages of HIV infection the function of both CD45RA + and CD45RO+ cells is affected. (J. Clin. Invest. 1994. 94:19471952.) Key words: human immunodeficiency virus $\cdot T$ cells - immunopathogenesis - alloantigen - CD45RA/CD45RO antigens
\end{abstract}

\section{Introduction}

Next to the quantitative loss of CD4+ T cells in later stages of infection, in early HIV infection, the T cell compartment of the immune system is qualitatively affected. Both CD4+ and CD8+ cells are impaired in their proliferative capacity. First, responses to recall antigen are diminished, whereas responses to allogeneic MHC (alloantigen) and mitogen decrease later in infection (1, 2 ). Addition of IL-2 or CD28 monoclonal antibodies (mAb) can partially restore the proliferative capacity of $T$ cells from

Address correspondence to Linde Meyaard, Department of Clinical Viro-Immunology, Central Laboratory of the Netherlands Red Cross Blood Transfusion Service, Plesmanlaan 125, 1066 CX Amsterdam, The Netherlands.

Received for publication 1 February 1994 and in revised form 20 June 1994.

J. Clin. Invest.

(C) The American Society for Clinical Investigation, Inc. 0021-9738/94/11/1947/06\$2.00

Volume 94, November 1994, 1947-1952
HIV-infected individuals, indicating that antigen-specific cells are present but do not respond $(3,4)$.

Peripheral blood $\mathrm{T}$ cells can be divided into two functionally different subsets based on the reciprocal expression of CD45RA and CD45RO. Responses to recall antigens are confined to $T$ cells with the CD45RO+ phenotype $(5,6)$. Moreover, as CD45RA+ cells lose CD45RA expression and concomitantly gain CD45RO expression after in vitro activation, it has been postulated that CD45RA and CD45RO expression define naive and memory cells, respectively (7). Along these lines, CD45RA + and CD45RO + $\mathrm{T}$ cells differ with respect to activation requirements, lymphokine secretion patterns, and expression of adhesion molecules $(7,8)$. The precursor frequency among CD45RO + cells to recall antigen is substantially higher than in CD45RO - cells, while both populations contain approximately equal numbers of precursors with the ability to respond to alloantigens (9). Recently, evidence was presented that $\mathrm{T}$ cells with the CD45RO+ phenotype may reconvert in vivo into the naive CD45RA+ phenotype (10-12). For this reason, CD45RA + and CD45RO + $T$ cell subsets might in fact not be identical to "naive" and "memory" cells, respectively.

In their inability to respond to recall antigen, but sustained reactivity to alloantigen and mitogens, $T$ cells in early HIV infection resemble naive cells. Indeed, functional and phenotypical evidence has been provided for a selective loss of memory cells in early infection $(4,13-16)$. In later stages of infection, functional defects are observed at normal naive/memory cell ratios, implying intrinsic defects of $\mathrm{T}$ cells next to the quantitative loss of memory cells. CD4 $+\mathrm{T}$ cells expressing CD45RO are preferentially infected by HIV in vitro and constitute the major population of HIV positive cells in infected individuals. This has lead to the suggestion that memory $T$ cell function is preferentially affected in HIV-infected individuals (17).

We addressed the question, whether functional loss of $\mathrm{T}$ cells is mainly confined to the memory $T$ cell subset or whether both naive and memory cells lose their function in the course of HIV infection. We studied the precursor frequency of alloreactive CD4+ T cells in HIV-infected individuals. Since alloantigen responsiveness is mediated by both CD45RA+ and CD45RO+ cells, this approach allowed us to study the deterioration of $\mathrm{T}$ cell responses in both populations. The precursor frequency of alloreactive CD45RA+ and CD45RO+CD4+ cells in HIV-infected individuals was followed over time. It appeared that both naive and memory $\mathrm{T}$ cells lose their ability to respond to alloantigen in the course of HIV infection.

\section{Methods}

Subjects. Peripheral blood from participants of the Amsterdam cohort study on HIV infection in homosexual men (18) and healthy HIV seronegative controls was used for isolation of cells. The frequent sam- 
pling and storage of viable lymphocytes from the cohort participants allowed us to study individuals over seroconversion and during the asymptomatic stages. From these individuals routinely lymphocyte immuno-phenotyping for CD4+ and CD8 + cells was performed by flow cytometry (normal range for CD4+ counts $0.55-1.55 \times 10^{9} /$ liter) and proliferative responses to $\mathrm{CD} 3 \mathrm{mAb}$ (normal value $>1100 \mathrm{cpm}$ ) were determined in whole-blood lymphocyte culture as described (19).

Responder cells. Peripheral blood mononuclear cells (PBMC) were isolated from heparinized blood by Ficoll-Paque density-gradient centrifugation. For longitudinal studies, cryopreserved viable cells were used. Purified CD4 + T cells ( $>$ 95\% CD3 +) were prepared by negative depletion using mAb directed against CD19 (CLB-CD19), CD16 (CLB-FcR gran1), CD14 (CLB-CD14) and CD8 (CLB-T8/4) (Central Laboratory of the Netherlands Red Cross Blood Transfusion Service, Amsterdam, The Netherlands) and immunomagnetic beads (DynabeadsM450; Dynal A.S., Oslo, Norway) as described (8).

PBMC were sorted in either CD4+ naive T cells (CD4+CD45RA+) or CD4+ memory $\mathrm{T}$ cells (CD4+CD45RO+) by staining with biotinlabeled CD8 (CLB-T8/4), streptavidin-RED670 (Gibco, Paisly, UK) and fluorescein isothiocyanate-labeled CD45RA (2H4-FITC, Coulter Immunology, Hialeah, FL) and phycoerytrin labeled CD45RO (UCHL1-PE, Dakopatts, Glostrup, Denmark) and subsequent cell sorting on a FACStar (Becton Dickinson Immunocytometry Systems, Mountain View, CA).

Stimulator cells. Monocytes were isolated from PBMC from 10 healthy donors, by counterflow centrifugal elutriation (20). The obtained monocyte preparation was $>95 \%$ pure and devoid of lymphocytes, thus preventing back stimulation due to $T$ cell growth factor production by stimulator cells induced by responder cells. Monocytes were pooled, viably frozen, and stored in liquid nitrogen until use. For all experiments the same stimulator cell pool was used. Cells were thawed and $5000 \mathrm{rad} \gamma$-irradiated before use.

Proliferative responses to CD3 antibodies. PBMC $\left(4 \times 10^{4}\right)$ were cultured for $4 \mathrm{~d}$ in $200 \mu \mathrm{l}$ Iscove's Modified Dulbecco's Medium (IMDM), 10\% fetal calf serum and antibiotics in the presence of CD3 mAb CLB T3/3 (CLB Biotechnology Department, Amsterdam, The Netherlands) immobilized on plastic (21). To measure proliferation 0.2 $\mu \mathrm{Ci}(7.4 \mathrm{kBq})\left[{ }^{3} \mathrm{H}\right]$ thymidine $(2 \mathrm{Ci} / \mathrm{mmol})$ was added during the last $18 \mathrm{~h}$ of culture. Thymidine incorporation was measured and proliferation is expressed as the mean cpm of triplicate cultures.

Proliferative responses to alloantigen. Irradiated stimulator cells were plated in graded numbers $\left(0-6 \times 10^{4} /\right.$ well $)$ in 96 -wells round bottom tissue culture plates (Greiner, Frickenhausen, Germany) in IMDM supplemented with $20 \%$ pooled human serum (HPS) and antibiotics. PBMC $\left(4 \times 10^{4} /\right.$ well $)$ of HIV-infected individuals or healthy sero-negative controls were added in a final volume of $150 \mu \mathrm{l}$. Cultures were maintained for $6 \mathrm{~d}$ at $37^{\circ} \mathrm{C}$. To measure proliferation $0.2 \mu \mathrm{Ci}(7.4$ $\mathrm{kBq})\left[{ }^{3} \mathrm{H}\right]$ thymidine $(2 \mathrm{Ci} / \mathrm{mmol})$ was added during the last $18 \mathrm{~h}$ of culture. Thymidine incorporation was measured and proliferation is expressed as the mean cpm of quadruplicate cultures.

Limiting dilution analysis. The frequency of alloreactive $\mathrm{T}$ cells was determined by limiting dilution analysis. Irradiated stimulator cells (4 $\times 10^{4}$ /well) were plated in IMDM supplemented with $20 \%$ HPS and antibiotics in 96-well round bottom tissue culture plates. Responder cells $(0,50,100,400,800,1600,3200$ /well $)$ were added in 24-fold in a final volume of $150 \mu \mathrm{l}$. Cultures were kept for $9 \mathrm{~d}$ at $37^{\circ} \mathrm{C}$ and $\left[{ }^{3} \mathrm{H}\right]$ thymidine was added during the last $18 \mathrm{~h}$ of culture. Positive responses were scored when the cpm were more than three SD above the mean of cpm from control cultures containing irradiated stimulator cells only. Frequency estimates were made using the "single hit Poisson model" by methods described by Strijbosch et al. (22).

\section{Results}

Decreased proliferative responses to allogeneic stimulator cells in HIV-infected individuals. From seven HIV-infected individuals and five healthy controls the proliferative response of PBMC

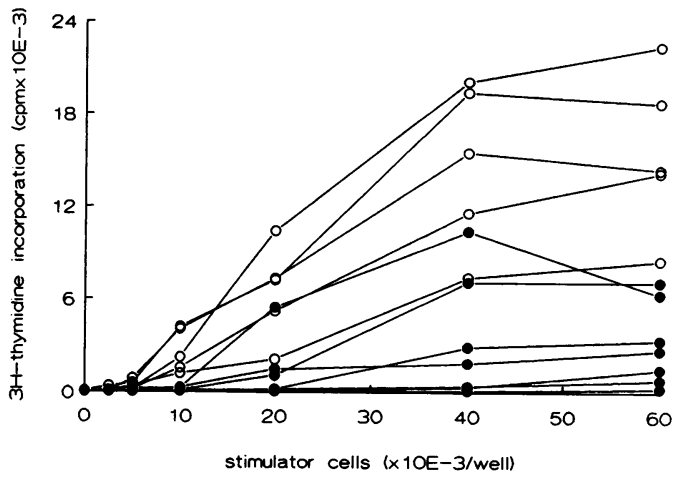

Figure 1. Decreased proliferative responses to allogeneic stimulator cells in HIV-infected individuals. Proliferative responses of PBMC (4 $\times 10^{4}$ ) of seven HIV-infected individuals $(\bullet)$ and five healthy seronegative controls $(0)$ to graded numbers of pooled irradiated allogeneic monocytes as stimulator cells $\left(0-6 \times 10^{4}\right)$. Proliferation is expressed as the mean cpm of quadruplicate cultures.

to graded numbers of irradiated pooled allogeneic monocytes was determined. The noninfected controls showed a proliferative response to 10,000 monocytes per well, while PBMC from the HIV-infected individuals did require more stimulator cells to elicit a proliferative response (Fig. 1). Moreover, the proliferative responses of PBMC from the HIV-infected men never reached the level of the response of PBMC from controls. These data confirm the previously reported decreased alloantigen-responsiveness of PBMC from HIV-infected individuals $(1,3)$.

Decreased precursor frequency of alloreactive CD4+ cells in HIV-infected individuals. We next examined the precursor frequency of alloreactive cells within the CD4+ $\mathrm{T}$ cell population of HIV-infected men and seronegative controls. The precursor frequency of alloreactive cells within the CD4+ subset in normal healthy donors ranged from 15 to 83 per $10^{4}$ CD4+ cells (Fig. 2). From the eight HIV-infected individuals analyzed, four had precursor frequencies below the range found for controls, while four fell within this range (Fig. 2). However, the highest precursor frequencies were consistently observed among controls.

Decreased alloreactive $T$ cells in both the naive and memory $T$ cell subset in HIV infection. We next separated naive and memory $\mathrm{T}$ cells by staining with CD45RA and CD45RO mAb and FACS sorting and examined the alloreactive $\mathrm{T}$ cell precursor frequency in both subsets of four HIV-infected individuals and four controls (Table I). Precursor frequencies ranged from 5 to 31 alloreactive $\mathrm{T}$ cells $/ 10^{4}$ in the noninfected controls, which is concordant with the data in Fig. 2, taking into account that CD45-subsets from both CD4+ and CD8+ cells were analyzed. In all seronegative individuals, the precursor frequency was higher in the CD45RO+ subset. In three out of four HIV-infected individuals precursor frequencies were substantially decreased as compared to the control measured in the same experiment. This affected both naive and memory $\mathrm{T}$ cells, resulting in a memory/naive ratio of alloreactive cells comparable to that of the controls. However, in one HIV-infected individual (Table I, Exp. 2), the precursor frequency of alloreactive cells in the naive subset was still normal, while the frequency in memory cells was decreased, resulting in an inverted ratio.

Proliferation is expressed as the mean cpm of responding wells at a responder cell density of 1600 cells per well. Prolifera- 


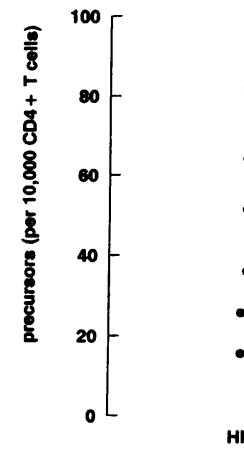

$\bullet$
$\bullet$
$\bullet$
$\bullet$
$\bullet$
HIV.
Figure 2. Decreased pre-
cursor frequency of allo-
reactive CD4+ cells in
HIV-infected individu-
als. Limiting dilution
analysis of the precursor
frequency of alloantigen-
responding CD4+ cells
of eight HIV-infected in-
dividuals (HIV+) and
eight healthy sero-nega-
tive controls (HIV-).
HIV+ $\quad$ CD4+ cells were cul-
tured for $9 \mathrm{~d}$ in graded

numbers $(50-3,200) /$ well in 24-fold on $40 \times 10^{3}$ irradiated allogeneic monocytes ( $5000 \mathrm{rad})$. Thresholds for determination of positive responses were defined by the mean cpm $+3 \mathrm{SD}$ of control cultures. Data represent alloreactive CD4+ cell precursor frequency expressed per $10^{4} \mathrm{CD} 4+$ cells as determined in four independent experiments. In each experiment two HIV-infected and two control individuals were examined.

tive responses of cells from HIV-infected individuals were decreased, indicating that not only the frequency of responding cells decreases but that also the magnitude of the response is affected in both the CD45RA+ as the CD45RO+ subset in HIV-infected individuals.

Longitudinal analysis of alloreactive naive and memory CD4+ $T$ cells in HIV-infected individuals. The finding that in one of the HIV-infected individuals depicted in Table I (Exp. 2 ), $T$ cell function was more affected in the memory than in the naive subset, might suggest a differential loss of $T$ cell function in these subsets, associated with the stage of HIV infection. This prompted us to study naive and memory $\mathrm{T}$ cell function in the course of HIV infection in four individuals. Cryopreserved PBMC obtained from different time points from four individuals were used for isolation of cells. We sorted CD4+ cells, to rule out the influence of differences in CD4+ cell counts, in CD45RA + and CD45RO+ cells. From each individual, one time-point before and three during HIV infection were studied (Fig. 3). Precursor cell frequencies varied from 17.7 to 148 per $10^{4} \mathrm{CD} 4+$ cells in the HIV-negative timepoints, with a memory/naive ratio varying from 0.90 to 2.83 . After HIV infection, in all individuals a decline of the CD4+ alloreactive precursor cell frequency was observed, occurring in both subsets. Individual $A$ had a very high alloreactive $T$ cell precursor frequency, which declined upon infection but at 60 mo was within the normal range. CD4 $+\mathrm{T}$ cell numbers and $\mathrm{T}$ cell reactivity to $\mathrm{CD} 3 \mathrm{mAb}$ declined with time, but $\mathrm{CD} 3 \mathrm{mAb}$ reactivity was only below control values at the last time-point. In individual $\mathrm{B}$, precursor frequencies in both subsets were stable until 30 mo after seroconversion, in agreement with stable CD4+ $T$ cell numbers and $T$ cell reactivity, and declined to 15 per $10^{4}$ at 56 mo (Fig. $3 \mathrm{~B}$ ). In contrast, individual $\mathrm{C}$, showed a rapid decline in CD4+ counts and $\mathrm{T}$ cell reactivity, which was below normal values at $27 \mathrm{mo}$. In parallel with this, alloreactive $T$ cell precursor frequencies in the naive and memory subset decreased to less than 6 per $10^{4}$. Individual $D$ had a defect in the downregulation of CD45RA expression after upregulation of CD45RO, resulting in absence of CD45RAcells, as was previously reported to occur in 5-8\% of the normal population $(23,24)$. We sorted CD45RA+CD45RO- (naive) and CD45RA+CD45RO+ (memory) cells. Both populations
Table I. Frequencies of Alloreactive Cell Precursors in the Naive and Memory Subset from HIV-infected Individuals and Controls*

\begin{tabular}{|c|c|c|c|c|c|}
\hline & \multicolumn{2}{|c|}{$\begin{array}{c}\text { Proliferation } \\
\text { [mean cpm (SEM)] }\end{array}$} & \multicolumn{2}{|c|}{$\begin{array}{c}\text { Precursors } \\
\text { (per } 10^{4} \text { cells) }\end{array}$} & \multirow{2}{*}{$\begin{array}{l}\text { Ratio } \\
\text { R0:RA }\end{array}$} \\
\hline & CD45RA+ & $\mathrm{CD} 45 \mathrm{RO}+$ & CD45RA+ & CD45RO+ & \\
\hline \multicolumn{6}{|l|}{ Exp. 1} \\
\hline HIV- & $1592^{\ddagger}(390)$ & $1087(280)$ & 8.1 & 9.0 & 1.11 \\
\hline HIV+ & 0 & $199(131)$ & $<0.1$ & $<0.1$ & \\
\hline \multicolumn{6}{|l|}{ Exp. 2} \\
\hline HIV- & $358(75)$ & $553(78)$ & 4.9 & 9.6 & 1.96 \\
\hline HIV+ & $350(64)$ & 717 (397) & 5.8 & 1.9 & 0.33 \\
\hline \multicolumn{6}{|l|}{ Exp. 3} \\
\hline HIV- & $455(115)$ & 474 (99) & 8.6 & 12.1 & 1.41 \\
\hline HIV+ & $110(0.6)$ & ND' & 1.2 & 1.9 & 1.58 \\
\hline \multicolumn{6}{|c|}{ Exp. 4} \\
\hline HIV- & $1793(340)$ & 1700 (259) & 19.1 & 31.2 & 1.63 \\
\hline $\mathrm{HIV}+$ & 497 (118) & $583(130)$ & 2.9 & 5.3 & 1.83 \\
\hline
\end{tabular}

* PBMC were sorted in CD45RA+ cells and CD45RO+ cells by FACS. Frequencies of alloreactive $T$ cell precursors were determined by limiting dilution analysis cells as described in Methods. In each experiment one HIV-infected individual and one noninfected control was tested. ${ }^{\ddagger}$ Mean proliferation (SEM) of responding wells at a responder cell concentration of 1600 cells/well. ' Precursor frequency of CD45RO+ cells divided by the precursor frequency in the CD45RA + subset.

'ND, not determined.

had a similar alloreactive $\mathrm{T}$ cell precursor frequency and both declined in parallel with CD3 mAb reactivity. Thus, in both the naive and the memory $T$ cell subset an equally rapid decline in alloantigen responsiveness can be observed in HIV-infected individuals.

Impaired proliferative responses of PBMC from HIV-infected individuals to CD3 antibodies. Thus, we obtained no evidence for a preferential loss of function of the CD45RO+ population in HIV-infected individuals. Still, the early loss of reactivity towards recall antigen has been amply documented. This discrepancy might possibly be explained by the fact that HIV progressively induces defects in $\mathrm{T}$ cell responsiveness, impairing responses to low level TCR triggering, i.e., antigenic peptides in context with MHC molecules early, but responses to strong stimuli, such as lectins, later in the course of infection. To investigate this, we studied the proliferative responses by PBMC from nine HIV-infected individuals compared to nine controls (Fig. 4). Indeed, the response to low density coated CD3 mAb was severely disturbed in all HIV-infected individuals tested, whereas the response to optimal coating of $\mathrm{CD} 3 \mathrm{mAb}$ was above $50 \%$ of controls in three of the HIV-infected subjects. Thus, the proliferative response of PBMC from HIV-infected individuals is increasingly disturbed with decreasing dose of antigen.

\section{Discussion}

Here, we demonstrate that the decreased proliferative response to alloantigen in HIV-infected individuals was associated with a decreased T cell precursor frequency to alloantigens. Analysis of four individuals followed over time revealed that the number of alloreactive $T$ cells decreased in both the naive (CD45RA+) 

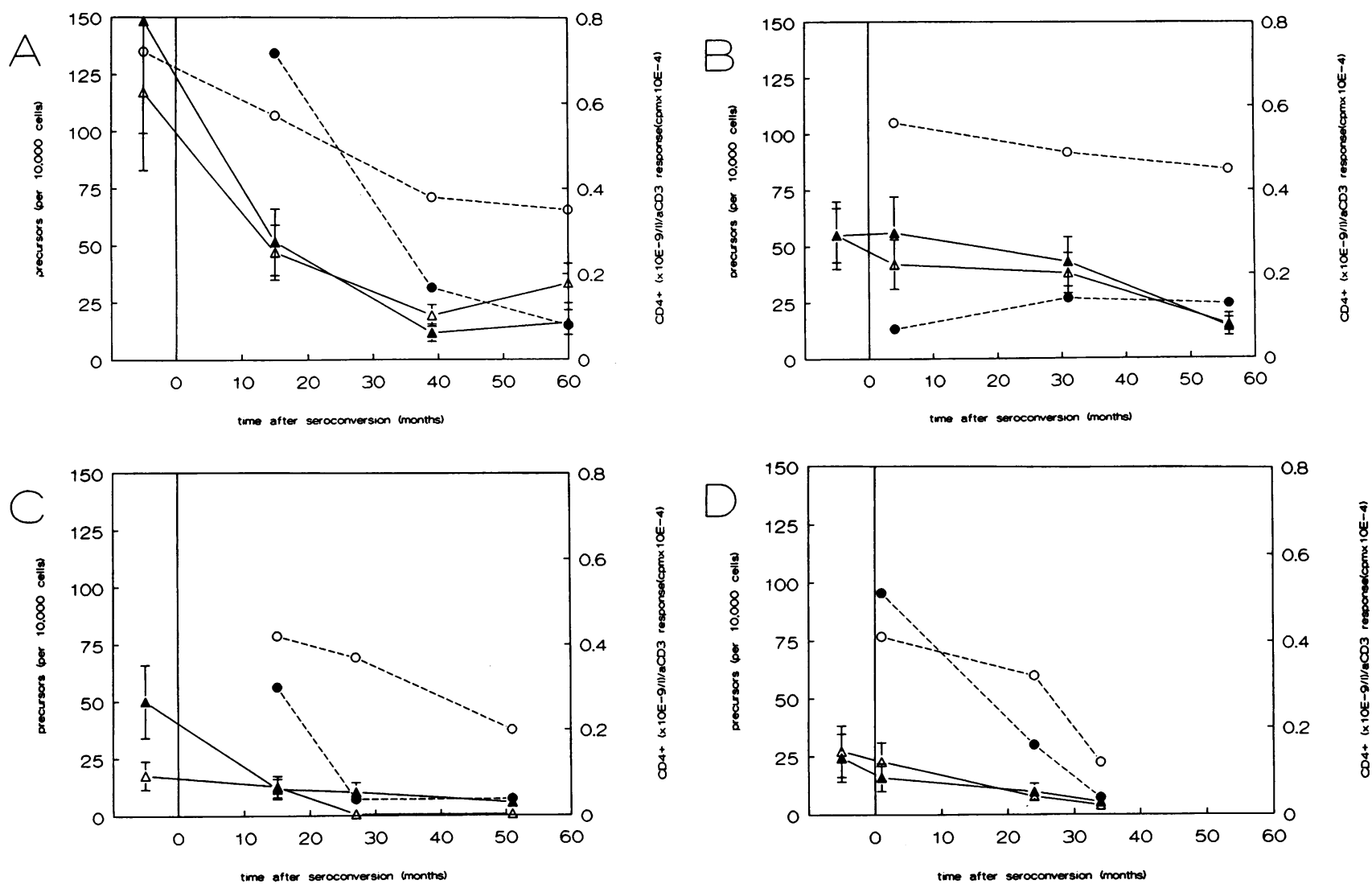

Figure 3. Longitudinal analysis of alloreactive naive and memory CD4+ T cells in HIV infected individuals. Frequencies of alloreactive precursors in CD4 + CD45RA $+(\triangle)$ and CD4 + CD45RO+ $(\Delta)$ T cells from four individuals $(A-D)$. From each individual, PBMC from one time-point before HIV-infection (more than 8 mo before seroconversion) and three time points during asymptomatic HIV infection were sorted in CD4+CD45RA+ and CD4+CD45RO+ cells and precursor frequencies were determined by limiting dilution analysis. All time points from one individual were measured in the same experiment. Data are expressed as precursor frequency per $10^{4}$ cells, bars represent $95 \%$ confidence interval. CD4+ T-cell numbers $\left(0,10^{9} / 1\right)$ and proliferative responses to CD3 $\mathrm{mAb}\left(\bullet, \mathrm{cpm} \times 10^{-4}\right)$ are depicted as determined by standard methods (see Methods).

and the memory (CD45RO+) CD4+ $\mathrm{T}$ cell subset. Loss of function occurred in both subsets with the same kinetics, suggesting that both naive and memory $\mathrm{T}$ cells from HIV-infected individuals are affected. Previously, a decline in precursor frequency of alloantigen specific cells in HIV-infected individuals was demonstrated (25). However, the reported frequency of
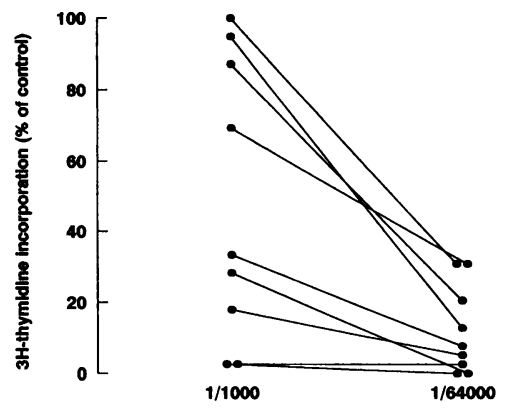

Figure 4. Decreased proliferative response to $\mathrm{CD} 3$ mAb by PBMC from HIVinfected individuals. Proliferative responses of PBMC $\left(4 \times 10^{4}\right)$ of nine HIV-infected individuals expressed as the percentage of the proliferation of PBMC from nine healthy sero-negative controls to optimal (1/1000) and

suboptimal (1/64000) dilution of ascites of CD3 mAb. Data were obtained in four independent experiments, each with two HIV-infected subjects and two controls. Mean proliferation of controls was set at $100 \%$ for each dilution of $\mathrm{mAb}$ and the proliferative responses from the HIV-infected subjects was calculated as percentage of control. alloreactive cells was extremely low (1-2 per $10^{4}$ PBMC in healthy controls) and comparable to that of recall-antigen specific precursors, which is not compatible with other reports (9).

In HIV-infected individuals, loss of both CD4+ and CD8+ $\mathrm{T}$ cell function occurs. First, $\mathrm{T}$ cell responses to recall antigen are lost. $T$ cells are not able to respond to antigen presented in the context of self-MHC, which also affects the self-restricted component of alloantigen-specific $T$ cell responses (26). Secondly, responses to alloantigens and mitogens are lost later in infection. Because we used purified T cells as responders cells, devoid of antigen presenting cells, the alloantigen recognition we studied per definition was not restricted by self-MHC (27). Several groups have reported evidence that in individuals where only recall antigen responses are affected, this defect can at least partially be explained by the quantitative loss of memory cells $(4,13-16)$. Using enriched subsets of T cells, Schnittman et al. (17) demonstrated that CD4+ T cells expressing CD45RO are preferentially infected in vitro by HIV and that CD45RO+ $T$ cells constitute the major population of HIV-infected cells in the peripheral blood in vivo. It is proposed that by preferential viral infection, HIV induces deficiency specifically in the memory compartment of CD4+ T cells. Using purified subsets however, Schnittman et al. demonstrate that CD45RO + T cells from HIV-infected individuals, unresponsive to recall antigen, are 
still able to respond to mitogens (17). Thus, these data can be interpreted as a preferential loss of MHC-restricted responses rather than a preferential loss of memory cell function. We now demonstrate that when $\mathrm{T}$ cells later in HIV infection lose their capacity to respond to alloantigen, both memory and naive cells are functionally affected. Impairment of both naive and memory cell function in HIV infection was previously indicated by Cayota et al. (28), who described decreased $\mathrm{T}$ cell proliferative responses to $\mathrm{CD} 3$ antibodies in naive cells from HIV-infected individuals.

Thus, no evidence for a preferential loss of function of the CD45RO + population in HIV-infected individuals is found, but possibly HIV induces a progressive lowering of $\mathrm{T}$ cell responsiveness, impairing responses to low level TCR triggering early, but responses to strong stimuli later in the course of infection. Indeed, stimulation of PBMC with dilutions of CD3 mAb demonstrated more impaired $\mathrm{T}$ cell proliferative responses to lower concentrations of $\mathrm{mAb}$. It might be that recall responses are preferentially affected simply due to lower precursor frequency to recall antigen than to alloantigens (9) although in disagreement with this, Schulick et al. (25) reported similar precursor frequencies to allo- and recall antigens in healthy individuals.

By which mechanism are the general $T$ cell defects induced during HIV infection? The low frequency of infected cells makes direct viral infection an unlikely explanation for $\mathrm{T}$ cell dysfunction. Furthermore, HIV resides mainly in memory cells, which excludes viral infection as a cause of naive $T$ cell dysfunction (17). Several mechanisms have been proposed as a systemic explanation for T cell dysfunction in HIV infection. Interaction of the viral envelope protein gp120 with CD4+ results in decreased $\mathrm{T}$ cell responses (29). Furthermore, overproduction of the immunosuppressive cytokines TGF- $\beta$ (30) and IL-10 (31) has been associated with decreased T cell function. The intracellular defect in T cells in HIV-infected individuals is not clear yet, but decreased cysteine levels in $\mathrm{T}$ cells have been shown to play a role in the immunodeficiency $(32,33)$. We previously hypothesized that the observed $\mathrm{T}$ cell defects might be the result of defects in antigen presentation due to infection of the accessory cells (34). T cells from HIV-infected individuals resemble anergic cells as defined in cell culture models. Anergy might be induced by lack of correct accessory molecules or inappropriate cytokine secretion by antigen presenting cells. Indeed, impaired IL-12 production by monocytes from HIV-infected individuals has been recently described (35). Not only primed (CD45RO+) $\mathrm{T}$ cells might become anergic after encountering antigen, but at their first encounter with antigen, CD45RA + cells might become unresponsive and fail to develop into memory cells. Thus, both memory and naive cells might become anergic by defective antigen presentation.

Taken together, in early HIV infection, recall antigen responses are affected by the selective quantitative loss of memory cells and by loss of the capacity of the remaining memory cells to respond to low-density antigen, while these cells retain a normal response to high density alloantigen and mitogens (4, $17,36)$. In later stages of infection, the function of both CD45RA + and CD45RO + cells is equally affected, leading to defects in alloantigen and mitogen responses. This implies that not only $T$ cell responses to antigens, to which the individual was previously exposed, are impaired in HIV infection. Generation of $\mathrm{T}$ cell memory is also abolished, compatible with low antibody responses to vaccination in late stage HIV-infected individuals (37). This might have important implications for vaccination strategies and might plead for prophylactic drugs rather than vaccination to protect late stage HIV-infected individuals from infection with various pathogens.

\section{Acknowledgments}

We wish to thank Erik Mul and Anton Tool for preparing the monocyte pool, Birgitta Breur-Vriesendorp, Michèl Klein, and René van Lier for technical advice and helpful discussions and Hanneke Schuitemaker for critical reading of the manuscript.

This study was supported by a grant (90-015) from the Dutch Ministry of Public Health and conducted as part of the Amsterdam Cohort Studies on AIDS. The authors are greatly indebted to all cohort participants for their continuous cooperation.

\section{References}

1. Clerici, M., N. Stocks, R. A. Zajac, R. N. Boswell, D. R. Lucey, C. S. Via, and G. M. Shearer. 1989. Detection of three different patterns of T helper cell dysfunction in asymptomatic, human immundeficiency virus-seropositive patients. J. Clin. Invest. 84:1892-1899.

2. Gruters, R. A., F. G. Terpstra, R. De Jong, C. J. M. Van Noesel, R. A. W. Van Lier, and F. Miedema. 1990. Selective loss of T-cell functions in different stages of HIV infection. Eur. J. Immunol. 20:1039-1044.

3. Shearer, G. M., D. C. Bernstein, K. S. K. Tung, C. S. Via, R. Redfield, S. Z. Salahuddin, and R. C. Gallo. 1986. A model for the selective loss of major histocompatibility complex self-restricted $\mathrm{T}$ cell immune responses during the development of acquired immune deficiency syndrome (AIDS). J. Immunol. 137:2514-2521.

4. Van Noesel, C. J. M., R. A. Gruters, F. G. Terpstra, P. Th. A. Schellekens, R. A. W. Van Lier, and F. Miedema. 1990. Functional and phenotypic evidence for a selective loss of memory T cells in asymptomatic HIV-infected men. $J$. Clin. Invest. 86:293-299.

5. Morimoto, C. N., N. L. Letvin, J. A. Distaso, W. R. Aldrich, and S. F. Schlossman. 1985. The isolation and characterization of the human suppressor inducer T cell subset. J. Immunol. 134:1508-1515.

6. Morimoto, C., N. L. Letvin, A. W. Boyd, M. Hagan, H. M. Brown, M. M. Kornacki, and S. F. Schlossman. 1985. The isolation and characterization of the human helper inducer T cell subset. J. Immunol. 134:3762-3769.

7. Sanders, M. E., M. W. Makgoba, and S. Shaw. 1988. Human naive and memory T cells: reinterpretation of helper-inducer and suppressor-inducer subsets. Immunol. Today. 9:195-198.

8. De Jong, R., M. Brouwer, F. Miedema, and R. A. W. Van Lier. 1991. Human CD8 + T lymphocytes can be divided into CD45RA + and CD45RO+ cells with different requirements for activation and differentiation. J. Immunol. 146:2088-2094.

9. Merkenschlager, M., L. Terry, R. Edwards, and P. C. L. Beverley. 1988. Limiting dilution analysis of proliferative responses in human lymphocyte populations defined by the monoclonal antibody UCHL1: Implications for differentia CD45 expression in T cell memory formation. Eur. J. Immunol. 18:1653-1661.

10. Bell, E. B., and S. M. Sparshott. 1990. Interconversion of CD45R subsets of CD4 T cells in vivo. Nature (Lond.). 348:163-166.

11. Michie, C. A., A. McLean, C. Alcock, and P. C. L. Beverley. 1992. Lifespan of human lymphocyte subsets defined by CD45 isoforms. Nature (Lond.). 360:264-265.

12. Tough, D. F. and J. Sprent. 1994. Turnover of naive- and memory-phenotype T cells. J. Exp. Med. 179:1127-1135.

13. De Martini, R. M., R. R. Turner, S. C. Formenti, D. C. Boone, P. C. Bishop, A. M. Levine, and J. W. Parker. 1988. Peripheral blood mononuclear cell abnormalities and their relationship to clinical course in homosexual men with HIV infection. Clin. Immunol. Immunopathol. 46:258-271.

14. Fletcher, M. A., S. P. Azen, B. Adelsberg, G. Gjerset, J. Hassett, J. Kaplan, J. C. Niland, T. Odom-Maryon, J. W. Parker, D. P. Stites, J. W. Mosley, and Transfusion Safety Study Group. 1989. Immunophenotyping in a Multicentre Study: The transfusion safety study experience. Clin. Immunol. Immunopathol. 52:38-47.

15. De Paoli, P., S. Battistin, M. Crovatto, M. L. Modolo, A. Carbone, U. Tirelli, and G. Santini. 1988. Immunologic abnormalities related to antigenaemia during HIV-1 infection. Clin. Exp. Immunol. 74:317-320.

16. Gruters, R. A., F. G. Terpstra, R. E. Y. De Goede, J. W. Mulder, F. De Wolf, P. T. A. Schellekens, R. A. W. Van Lier, M. Tersmette, and F. Miedema. 1991. Immunological and virological markers in individuals progressing from seroconversion to AIDS. AIDS (Phila.). 5:837-844.

17. Schnittman, S. M., H. C. Lane, J. Greenhouse, J. S. Justement, M. Baseler, and A. S. Fauci. 1990. Preferential infection of $\mathrm{CD}^{+}{ }^{+}$memory $\mathrm{T}$ cells by human immunodeficiency virus type 1 : Evidence for a role in the selective T-cell func- 
tional defects observed in infected individuals. Proc. Natl. Acad. Sci. USA. 87:6058-6062.

18. De Wolf, F., J. M. A. Lange, J. T. M. Houweling, R. A. Coutinho, P. Th A. Schellekens, J. Van der Noordaa, and J. Goudsmit. 1988. Numbers of CD4+ cells and the levels of core antigens of and antibodies to the human immunodeficiency virus as predictors of AIDS among seropositive homosexual men. J. Infect. Dis. 158:615-622.

19. Schellekens, P. Th. A., M. Th. L. Roos, F. De Wolf, J. M. A. Lange, and F. Miedema. 1990. Low T-cell responsiveness to activation via CD3/TCR is a prognostic marker for AIDS in HIV-1 infected men. J. Clin. Immunol. 10:121127.

20. Figdor, C. G., W. S. Bont, I. Touw, J. De Roos, E. E. Roosnek, and J. De Vries. 1982. Isolation of functionally different human monocytes by counterflow centrifugation elutriation. Blood. 60:46-54.

21. Van Lier, R. A. W., M. Brouwer, V. I. Rebel, C. J. M. Van Noesel, and L. A. Aarden. 1989. Immobilized anti-CD3 monoclonal antibodies induce accessory cell-independent lymphokine production, proliferation and helper activity in human $T$ lymphocytes. Immunology. 68:45-50.

22. Strijbosch, L. W. G., R. J. M. M. Does, and W. A. Buurman. 1988. Computer aided design and evaluation of limiting dilution and serial dilution experiments. Int. J. Bio-med. Comput. 23:279-290.

23. Schwinzer, R., and K. Wonigeit. 1990. Genetically determined lack of CD45 $R^{-} \mathrm{T}$ cells in healthy individuals. Evidence for a regulatory polymorphism of CD45R antigen expression. J. Exp. Med. 171:1803-1808.

24. Matsuyama, T., A. Yamada, D. M. Rothstein, K. C. Anderson, S. F. Schlossman, and C. Morimoto. 1991. CD45 isoforms associated with distinct functions of CD4 cells derived from unusual healthy donors lacking CD45RAT lymphocytes. Cell. Immunol. 137:406-419.

25. Schulick, R. D., M. Clerici, M. J. Dolan, and G. M. Shearer. 1993. Limiting dilution analysis of interleukin-2-producing $T$ cells responsive to recall and alloantigens in human immunodeficiency virus-infected and uninfected individuals. Eur. J. Immunol. 23:412-417.

26. Clerici, M., C. S. Via, D. R. Lucey, E. Roilides, P. A. Pizzo, and G. M. Shearer. 1991. Functional dichotomy of CD4+ T helper lymphocytes in asymptomatic human immunodeficiency virus infection. Eur. J. Immunol. 21:665-670.
27. Via, C. S., G. C. Tsokos, N. I. Stocks, M. Clerici, and G. M. Shearer. 1990. Human in vitro allogeneic responses. Demonstration of three pathways of T helper cell activation. J. Immunol. 144:2524-2528.

28. Cayota, A., F. Vuillier, D. Scott-Algara, V. Feuillie, and G. Dighiero. 1992. Impaired proliferative capacity and abnormal cytokine profile of naive and memory CD4 T cells from HIV-seropositive patients. Clin. Exp. Immunol. $88: 478-483$.

29. Chirmule, N., V. S. Kalayanaraman, N. Oyaizu, H. B. Slade, and S. Pahwa. 1990. Inhibition of functional properties of tetanus-specific T-cell clones by envelope glycoprotein gp120 of human immunodeficiency virus. Blood. 75:152-159.

30. Kekow, J., W. Wachsman, J. A. McCutchan, M. Cronin, D. A. Carson, and M. Lotz. 1990. Transforming growth factor beta and non-cytopathic mechanisms of immunodeficiency in human immunodeficiency virus infection. Proc. Natl. Acad. Sci. USA. 87:8321-8325.

31. Clerici, M., and G. M. Shearer. 1993. A $T_{H} 1 \rightarrow T_{H} 2$ switch is a critical step in the etiology of HIV infection. Immunol. Today. 14:107-111.

32. Staal, F. J. T., S. W. Ela, M. Roederer, M. T. Anderson, and L. A. Herzenberg. 1992. Gluthatione deficiency and human immunodeficiency virus infection. Lancet (N. Am. Ed.). 339:909-912.

33. Dröge, W., H. P. Eck, and S. Mihm. 1992. HIV-induced cysteine deficiency and T-cell dysfunction - a rationale for treatment with $\mathrm{N}$-acetylcysteine. Immunol. Today. 13:211-214.

34. Meyaard, L., H. Schuitemaker, and F. Miedema. 1993. T-cell dysfunction in HIV infection: Anergy due to defective antigen presenting cell function? Immunol. Today. 14:161-164.

35. Chehimi, J., S. E. Starr, I. Frank, A. D'Andrea, X. Ma, R. R. MacGregor, J. Sennelier, and G. Trinchieri. 1994. Impaired interleukin 12 production in human immunodeficiency virus infected patients. J. Exp. Med. 179:1361-1366.

36. Miedema, F., M. Tersmette, and R. A. W. Van Lier. 1990. AIDS pathogenesis: a dynamic interaction between HIV and the immune system. Immunol. Today. 11:293-297.

37. Steinhoff, M. C., B. S. Auerbach, K. E. Nelson, D. Vlahov, R. L. Becker, M. H. Graham, D. H. Schwartz, A. H. Lucas, and R. E. Chaisson. 1991. Antibody responses to haemophilus influenzae type B vaccines in men with human immunodeficiency virus infection. N. Engl. J. Med. 325:1837-1842. 